\title{
Pelatihan Pemasaran Melalui Media Sosial Dalam Meningkatkan Penjualan Produk Umkm di PLUT KUMKM Tulungagung
}

\author{
Eni Widhajati, Nurani, Eni Minarni, Mokhamad Eldon \\ Universitas Tulungagung \\ widhajati.2017@gmail.com'nuraniazis@gmail.com \\ eminarni944@gmail.com, eldon.personal@gmail.com
}

\begin{abstract}
Micro, Small and Medium Enterprises play an important role in improving the economy and welfare of the community. The ability to compete and market products is one of the spearheads for business actors to exist and be competitive. There are many factors that influence the success of a business, however how a product can dominate the market is one of the priorities that business actors must do. In the era of the Industrial Revolution 4.0, business people can no longer rely on conventional marketing, they must also start marketing their products online. This shift in the marketing model must be carried out immediately by business actors so that their products are able to compete in the global market. In this context, the business actors have been assisted by PLUT KUMKM Tulungagung which have experienced in solving many problems in terms of marketing,. The purpose of this activity is to provide knowledge about the use of social media as a marketing medium and provide skills to MSME owners in increasing sales of their products. The method used in this activity is training and mentoring. The results of the training and mentoring activities besides increasing knowledge are expected that business actors will also be able to use social media as a means of product promotion and marketing so that sales can increase.
\end{abstract}

Keywords: Training; MSME Product Marketing; Social Media

Abstrak

Usaha Mikro Kecil Menengah berperan penting dalam meningkatkan perekonomian dan kesejahteraan masyarakat. Kemampuan bersaing dan pemasaran produk menjadi salah satu ujung tombak agar pelaku usaha dapat eksis dan berdaya saing. Banyak faktor yang mempengaruhi keberhasilan suatu usaha, namun bagaimana suatu produk dapat menguasai pasar menjadi salah satu prioritas yang harus dilakukan oleh pelaku usaha. Pada era Revolusi Industri 4.0 pelaku usaha tidak dapat lagi mengandalkan pemasaran konvensional, mereka juga harus mulai memasarkan produknya secara online. Pergeseran model pemasaran ini harus segera dilakukan oleh pelaku usaha agar produknya mampu bersaing dipasar global.

Pelaku usaha binaan PLUT KUMKM Tulungagung banyak mengalami kendala dalam hal pemasaran, pelaku usaha masih mengandalkan pemasaran konvensional dan belum memanfaatkan media social secara maksimal sebagai sarana pemasaran produknya.

Tujuan kegiatan ini adalah untuk memberikan pengetahuan tentang pemanfaatan media social sebagai media pemasaran dan memberikan ketrampilan kepada pemilik UMKM dalam meningkatkan penjualan produknya. Metode yang digunakan dalam kegiatan ini pelatihan dan pendampingan. Hasil dari kegiatan disamping meningkatkan pengetahuan diharapkan pelaku usaha juga mampu memanfaatkan sosial media sebagai sarana promosi dan pemasaran produk sehingga penjualan dapat meningkat.

Kata Kunci: Pelatihan; Pemasaran Produk; Media Sosial 


\section{A. PENDAHULUAN}

Usaha Mikro Kecil Menengah berperan penting dalam meningkatkan perekonomian dan kesejahteraan masyarakat. Kriteria Usaha Mikro Kecil danMenengah (UMKM) telah diatur oleh Undang-Undang No.20 tahun 2008. Besarnya omset dan aktiva akan menentukan masuk kriteria manakah usaha yang dilakukan, apakah masuk kriteria mikro, kecil atau menengah.Pengelolaan usaha dalam suatu usaha sangat penting dilakukanagar perusahaan dapat tetap eksis, cepat berkembang dan berdaya saing. Dengan pengelolaan usaha yang baik akan dapat dilihat bagaimana usaha tersebut dapat berkembang dari usaha mikro menjadi usaha kecil, usaha kecil menjadi usaha menengah demikian halnya untuk usaha menengah akan meningkat menjadi usaha besar. Salah satu poin hasil kinerja suatu usaha akan dikatakan bagus apabila usaha tersebut mengalami kenaikan omset dari waktu kewaktu. Dalam hal ini pemasaran menjadi salah satu ujung tombak dalam meningkatkan omset suatu usaha. Promosi dan Pemasaran produk yang tepat sasaran serta sesuai dengan kebutuhankonsumen dengan metode yang tepat akan dapat membantu meningkatkan penjualan suatu produk. Kementrian Koperasidan UKM melalui PLUT KUMKM melakukan program konsultasi dan pendampingan dengan menyediakan tenaga konsultan yang meliputi Konsultan Bidang Kelembagaan, Konsultan Bidang Produksi, Konsultan Bidang Pembiayaan, Konsultan Bidang Pemasaran dan Konsultan Bidang SDM. Masing-masing Konsultan mempunyai bidang pendampingan sesuai dengan tupoksi yang telah ditentukan. Agar pelaksanakan pendampingan dapat berjalan lancar, tepat sasaran dan sesuai dengan yang harapan. PLUT KUMKM dalam melaksanakan pendampingan diperlukan sinergi dengan Instansi terkait antara lain Dinas Kesehatan, Per Bankan, Lembaga keuangan lainnya dan Universitas. Dalam hal pendampingan legalitas usaha Konsultan Bidang Kelembagaan yang membidangi bersinergi dengan Dinas Kesehatan, BPOM, Halal dan lain sebagainya. Pendampingan Kemasan Produk Konsultan Bidang Produksi bersinergi dengan rumah kemasan, pendampingan pendanaan Konsultan Bidang Pembiayaan bersinergi dengan Bank dan Lembaga Keuangan terkait. Demikian halnya untuk pemasaran produk dan peningkatan SDM pelaku usaha. PLUT-KUMKM memberikan jasa layanan nonfinancial sebagai solusi atas permasalahan yang dihadapi oleh pelaku usaha.

Permasalahan pemasaran produk menempati tingkat teratas dalam pendampingan ke pelaku usaha. Hal ini disebabkan pemasaran produk yang dilakukan oleh pelaku usaha masih banyak yang mengandalkan pemasaran konvensional. Masih rendahnya kemampuan sumber daya manusia dalam memanfaatkan media social sebagai salah satu sarana pemasaran disamping sarana pemasaran digital lainnya menyebabkan daerah pemasaran menjadi terbatas. Jangkauan pemasaran konvensional yang selama ini dilakukan pelaku usaha hanya di Tulungagung dan kota di sekitarnya saja. Data pelaku usaha binaan PLUT KUMKM yaitu : 
Tabel 1. Data UMKM Tahun 2019

\begin{tabular}{|c|c|c|c|c|}
\hline No & Jenis Usaha & Nama Produk & Modal (Rp) & $\begin{array}{l}\text { Omset per } \\
\text { Bulan (Rp) } \\
\end{array}$ \\
\hline 1 & Makan Minum & UD Rosella NS & 15.000 .000 & 2.000 .000 \\
\hline 2 & Kuliner Makanan & WJT & 25.000 .000 & 10.000 .000 \\
\hline 3 & $\begin{array}{l}\text { Kripik Singkong Pedas } \\
\text { Manis }\end{array}$ & NIFA & 1.000 .000 & 1.500 .000 \\
\hline 4 & Aneka Rajut & Amy Collection & 7.500 .000 & 1.000 .000 \\
\hline 5 & Kripik Pisang Sale & Hanana & 10.000 .000 & 3.000 .000 \\
\hline 6 & Kripik Pisang & AL BISMA & 2.000 .000 & 1.000 .000 \\
\hline 7 & Donat Kentang & Donken Tulungagung & 2.500 .000 & 1.000 .000 \\
\hline 8 & Kerajinan Ecoprint & Nawrah Ecoprint & 5.000 .000 & 3.500 .000 \\
\hline 9 & Bantal, Sarung Aqua, dll & Noque Craft & 10.000 .000 & 2.000 .000 \\
\hline 10 & Kue Kering & Jevo 'Cookies & 50.000 .000 & 3.000 .000 \\
\hline 11 & Makanan Basah & Sop Duren Mas Andri & 2.600 .000 & 2.500 .000 \\
\hline 12 & Telor Asin & $\mathrm{BBB}$ & 7.000 .000 & 1.000 .000 \\
\hline 13 & Makanan & Gameli Rizqi & 5.000 .000 & 1.000 .000 \\
\hline 14 & Kripik Singkong & Langgeng & 2.500 .000 & 2.000 .000 \\
\hline 15 & Makaroni Goreng & $\begin{array}{l}\text { Rumah Kue Chocow } \\
\text { Boy }\end{array}$ & 5.000 .000 & 3.000 .000 \\
\hline 16 & Perkebunan & Sumari Blimbing & 50.000 .000 & 2.500 .000 \\
\hline 17 & Kuliner & $\begin{array}{l}\text { Masgal Geprek } \\
\text { Laperpool }\end{array}$ & 7.000 .000 & 2.000 .000 \\
\hline 18 & Sari Kedelai dan Cemilan & He2 Tridi & 5.000 .000 & 1.500 .000 \\
\hline 19 & Rajut & $\begin{array}{l}\text { Omah Rajut Jasmine } \\
\text { Collection }\end{array}$ & 5.000 .000 & 2.500 .000 \\
\hline 20 & Makan Minum & Anisa & 3.000 .000 & 1.500 .000 \\
\hline 21 & Makan Minum & Sri Rejeki & 2.000 .000 & 3.000 .000 \\
\hline 22 & Souvenir & Dun Creative & 2.000 .000 & 1.500 .000 \\
\hline 23 & Kuliner & Jenang Sumiran & 500.000 & 1.500 .000 \\
\hline 24 & Makan Minum & Aby's Kitchen & 2.500 .000 & 1.000 .000 \\
\hline 25 & Aneka Kripik & Allen Ndutz & 15.000 .000 & 2.000 .000 \\
\hline 26 & Makanan & Lina Cakes & 10.000 .000 & 2.500 .000 \\
\hline 27 & Kripik & $\begin{array}{l}\text { Kripik Usus Bebek } \\
\text { Bunda Aty }\end{array}$ & 5.000 .000 & 3.000 .000 \\
\hline 28 & Wingko & Wingko Bunda O’om & 2.000 .000 & 2.500 .000 \\
\hline 29 & Pembuatan Kripik & $\begin{array}{l}\text { Kripik Agya Bu } \\
\text { Marik }\end{array}$ & 10.000 .000 & 2.000 .000 \\
\hline 30 & Aneka Rajut & Iqna Handmade & 2.000 .000 & 1.500 .000 \\
\hline
\end{tabular}

Sumber :Data UMKM PLUT KUMKM Tulungagung,2019 


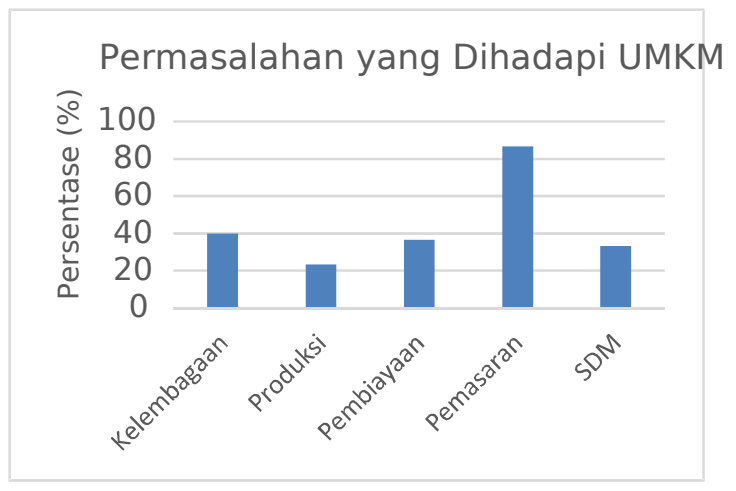

Diagram diatas menunjukkan bahwa permasalahan pemasaran menempati tingkat tertinggi dari permasalahan yang dihadapi oleh pelaku usaha.

\section{B. PELAKSANAANDANMETODE}

Permasalahan yang dihadapi mitra adalah rendahnya pengetahuan dalam pemanfaatan media social sebagai sarana pemasaran dalam meningkatkan penjualan. Dengan permasalahan tersebut diatas kegiatan pengabdian kepada masyarakat yang akan dilaksanakan adalah berupa sosialisasi dan pelatihan media sosial.

Tahapan-tahapan dalam pelaksanaan meliputi:

1. Tahapan pertama dari kegiatan pengabdian masyarakat adalah tahap persiapan, meliputi persiapan materi pelatihan, persiapan tempat pelatihan, persiapan sarana dan prasarana.

2. Tahapan kedua adalah tahap pelaksanaan, dimulai dengan mengidentifikasi tingkat pengetahuan dan media social dengan cara melakukan tanyajawab antara trainer (pelatih) dengan peserta.

3. Tahapan ketiga peserta diberikan sosialisasi tentang pemasaran dengan menggunakan media sosial dan dilanjutkan pelatihan dengan materi : cara buat akun for business, mengunggah foto produk, melakukan edit foto melalui fitur dari facebook dan instagram.

4. Tahapan berikutnya dalam kegiatan pengabdian kepada masyarakat adalah tahap evaluasi yaitu menilai kemampuan peserta pelatihan dalam menggunakan media social sebagai sarana pemasaran produknya.

\section{HASIL DAN PEMBAHASAN}

Kegiatan Pengabdian Kepada Masyarakat yang dilakukan oleh Tim Pengabdian Kepada Masyarakat berupa pemberian materi melalui ceramah dan praktek, kegiatan ini berlangsung 2 hari, pada hari pertama tanggal 24 Juli 2019 dilakukan pemberian materi pemanfaatan media social dalam melakukan pemasaran untuk meningkatkan penjulan produk UMKM, Hari kedua tanggal 25 Juli 2019 dilakukan pelatihan praktek pemanfatan media social sebagai sarana pemasaran memperluas daerah pemasaran. Media Sosial yang digunakan antara Facebook dan Instagram 
Gambar 2. Pelaksanaan Pengabdian Masyarakat
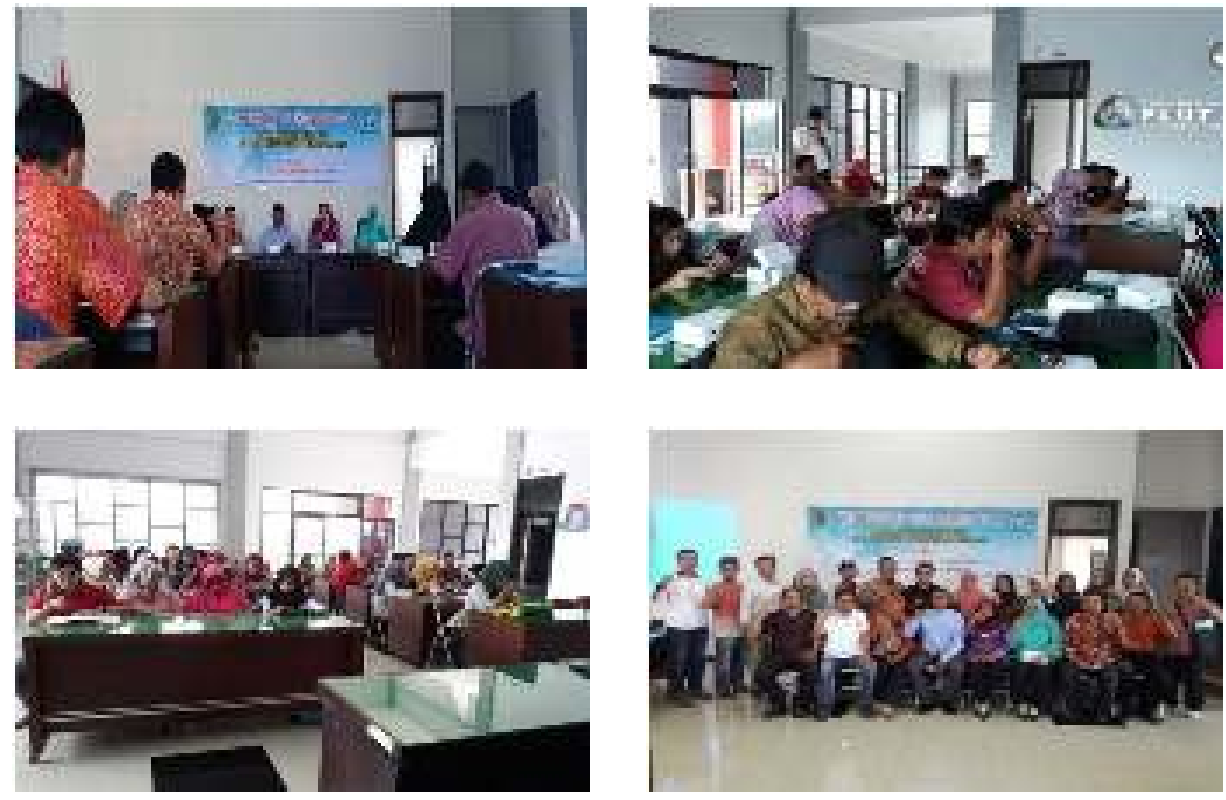

Gambar 3. Grafik Hasil Sosialisasi Tentang Pemasaran Melalui Media Sosial

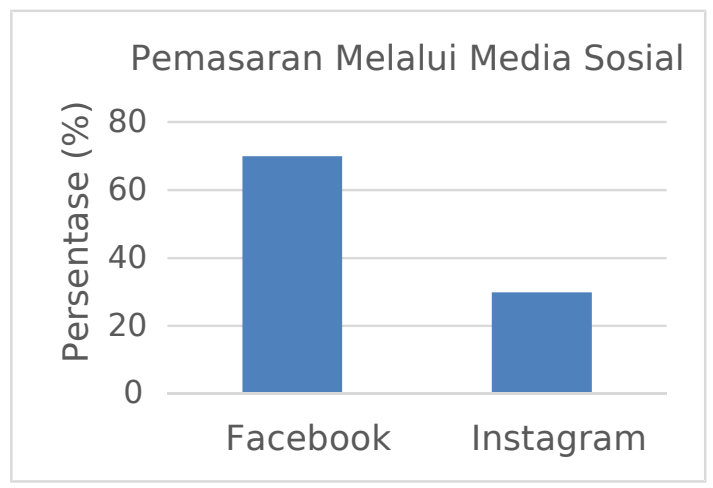

Berdasarkan grafik diatas, diketahui para peserta pelatihan dalam pengetahuan dalam penerapan media social facebook lebih besar dari pada instragam, sehingga mereka lebih mudah memahami fitur-fitur di facebook dari pada instagram atau media lain. Selanjutnya Tim pengabdian member pelatihan membuat akun,contoh facebook for business dapat dilihat dalam gambar berikut : 
Gambar 4. Gambar Hasil Kegiatan Membuat Konten Dan Tampilan Foto Produk Melalui Facebook
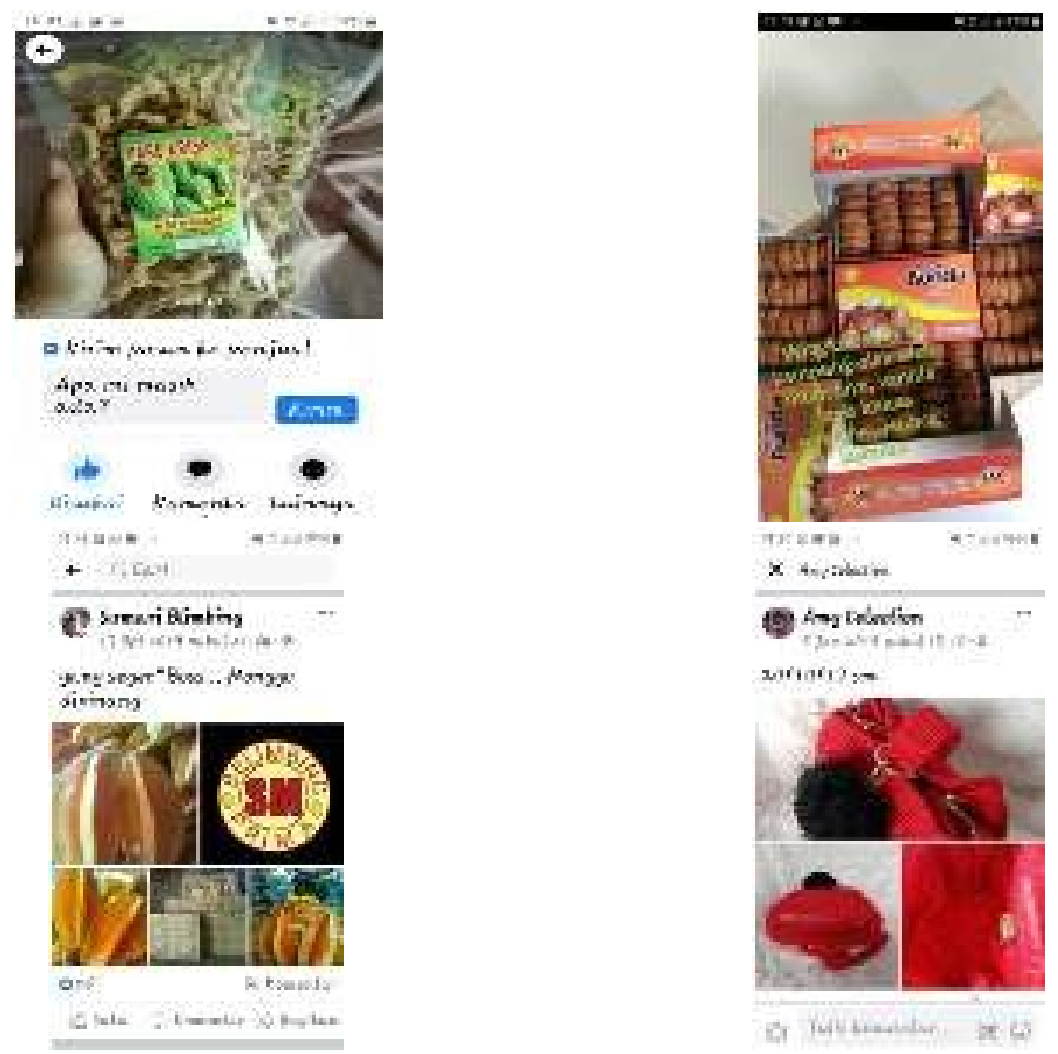

Sesi selanjutnya yaitu pelatihan membuat konten bisnis di media sosial dan pelatihan memposting konten promosi produk dan memberikan keterangan yang menarik konsumen.

Gambar 5. Gambar Konten Dan Tampilan Foto Produk Untuk Promosi Melalui Instagram
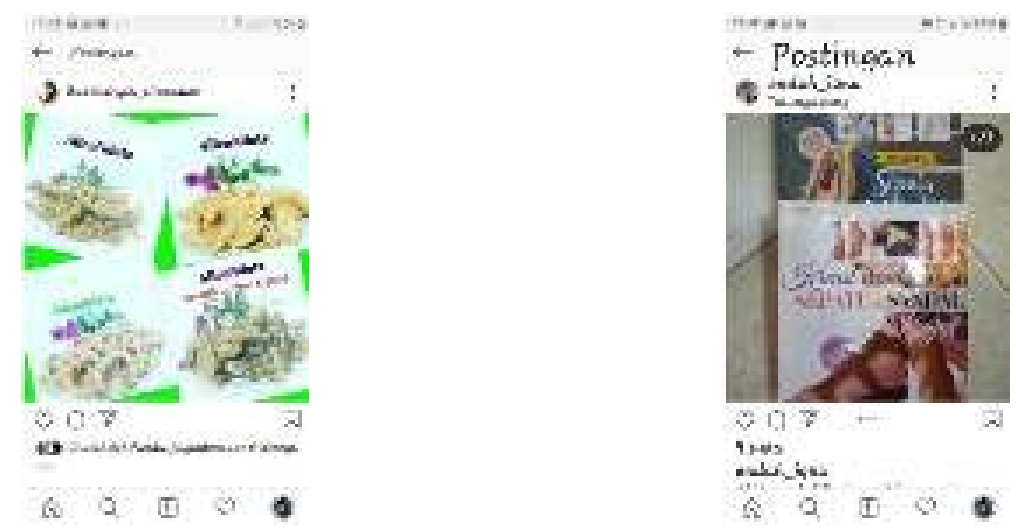

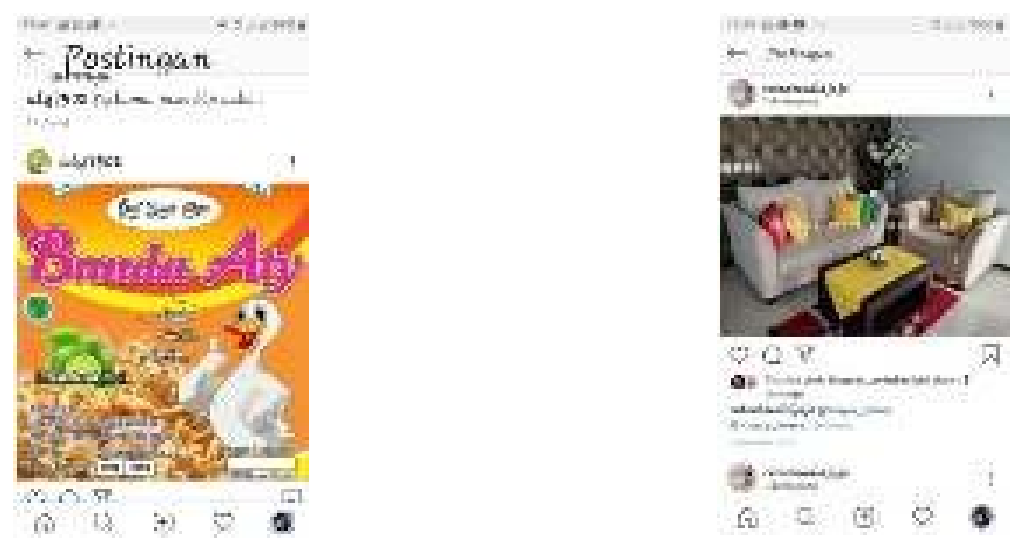

Dalam pelatihan diberikan cara berkomunikasi dengan pelanggan facebook dan instagram dan bagaimana cara mempromosikan produk agar menarik. Berdasarkan hasil evaluasi tim pengabdian masyarakat para peserta pelatihan dapat mempraktekkan materi dengan cukup baik dalam hal ini dilihat dalam penggunaan media social untuk sarana promosi dan memasarkan produk mereka. Setelah diberikan pelatihan peserta mengakui bahwa mereka telah bertambah pengetahuan dan ketrampilannya dalam pemanfaatan media social seperti facebook dan instagram dalam memasarkan dan mempromosikan produknya. Dan para peserta pelatihan menjadi lebih memahami peranan media social dalam memperluas daerah pemasaran sehingga bisa meningkatkan penjualan.

\section{PENUTUP}

Simpulan

Pelatihan pemasaran produk dengan media social facebook dan instagram yang telah dilaksanakan mampu meningkatkan pengetahuan dan ketrampilan. Dengan menggunakan media social sebagai sarana pemasaran dan promosi bisa dipakai juga untuk memperluas daerah pemasaran produk UMKM, sehingga dengan media tersebut diharapkan dapat meningkatkan omset penjualan.

Saran

Kegiatan yang akan datang perlu dilakukan fasilitasi para peserta pelatihan supaya dapat meningkatkan kemampuan dan pemanfaatan tehnologi untuk memajukan usaha UMKM.

\section{E. DAFTAR PUSTAKA}

BasuSwastha DH,2002,PengantarBisnisModern,Edisi 3, Yogyakarta: Liberty.

Djaslim Saladin dan Yevis Oesman, 2003. Manajemen Pemasaran: Analisis, Perencanaan, Pelaksanaan dan Pengendalian. Bandung: Linda Karya 
Fenni Rinaldi. 2013. Pengertian, Konsep, dan Perencanaan Strategi Manajemen Pemasaran. Tersedia dari : URL: https://www.kembar.pro/2015/05/manajemen-pemasaran-konseporientasi.html

https://www.kembar.pro/2015/05/manajemen-pemasaran-konsep-orientasi.html http://www.pengertianku.net/2015/05/pengertian-manajemen-pemasaran-danfungsinya.html

http://nichonotes.blogspot.co.id/2015/02/manajemen-pemasaran.html http://ahlimanajemenpemasaran.com/2017/07/merancang-strategi-komunikasipemasaran-terpadu-yang-hebat/

http://www.seputarilmu.com/2016/01/pengertian-tujuan-dan-fungsi$\underline{\text { manajemen.html }}$

https://www.jurnal.id/id/blog/2017/5-konsep-penting-dalam-manajemenpemasaran

https://www.dictio.id/t/strategi-pemasaran-marketing-strategy/2328 https://blog.jejualan.com/5-teknik-pemasaran-e-commerce-untuk-penjualan/ https://media.neliti.com/media/publications/157700-ID-e-commerce-sebagaipendukung-pemasaran-p.pdf

https://seoanaksholeh.com/marketing/pemasaran-melalui-media-sosial https://www.niagahoster.co.id/blog/social-media-marketing/ https://media.neliti.com/media/publications/124068-ID-none.pdf

Nurul Saputro. 2020. Manajemen Pemasaran. Tersedia dari ; URL : http://rocketmanajemen.com/manajemen-pemasaran-2/

Puntoaji, Danis.2011. Meningkatkan Penjualan Melalui Media Sosial, Jakarta: Gramedia Pustaka Utama

Rinaldi Ferry, Manajemen Pemasaran. "Pengertian Manajemen Pemasaran, Konsep dan Perencanaan Strategi Manajemen Pemasaran"

Swastha D.H. danIrawan.2008. ManajemenPemasaran modern.Edisike 13 BPFE Yogyakarta. 